\title{
HCN1 channels constrain DHPG-induced LTD at hippocampal Schaffer collateral-CAl synapses
}

\author{
Tursonjan Tokay, ${ }^{1,3}$ Marco Rohde, ${ }^{1,3}$ Sabine Krabbe, ${ }^{1}$ Mirko Rehberg, ${ }^{1}$ \\ Roland A. Bender, ${ }^{2}$ Rüdiger Köhling, ${ }^{1}$ and Timo Kirschstein ${ }^{1,4}$ \\ ${ }^{1}$ Institute of Physiology, University of Rostock, 18055 Rostock, Germany; ${ }^{2}$ Institute of Anatomy I, University of Hamburg, \\ 20246 Hamburg, Germany
}

\begin{abstract}
HCN channels play a fundamental role in determining resting membrane potential and regulating synaptic function. Here, we investigated the involvement of HCN channels in basal synaptic transmission and long-term depression (LTD) at the Schaffer collateral-CAl synapse. Bath application of the HCN channel blocker ZD7288 (10 $\mu$ M) caused a significant increase in synaptic transmission that was due to an enhancement in AMPA receptor-mediated excitatory postsynaptic potentials. This enhancement was accompanied by a significant decrease in the paired-pulse ratio (PPR), suggesting a presynaptic mechanism. Experiments with the irreversible use-dependent NMDA receptor blocker MK-801 showed that ZD7288 led to an increase in glutamate release probability. LTD induced by brief application of (RS)-3, 5-dihydroxyphenylglycine (DHPG, $100 \mu \mathrm{M}, 10 \mathrm{~min}$ ) was significantly enhanced when HCN channels were blocked by ZD7288 $(10 \mu \mathrm{M})$ prior to DHPG application. Moreover, the concomitant increase in PPR after DHPG-induced LTD was significantly larger than without ZD7288 bath application. Conversely, ZD7288 application after DHPG washout did not alter DHPG-LTD. A significant enhancement of DHPG-LTD was also observed in HCN1-deficient mice as compared with wild types. However, LTD induced by low-frequency stimulation (LFS) remained unaltered in HCN1-deficient mice, suggesting a differential effect of HCN1 channels on synaptic plasticity constraining DHPG-LTD, but not LFS-LTD.
\end{abstract}

Long-term depression (LTD) is a form of synaptic plasticity in hippocampus elicited by different types of synaptic stimulation. Activation of group I metabotropic glutamate receptors (mGluRs) with (RS)-3,5-dihydroxyphenylglycine (DHPG) induces LTD at CA1 synapses (Palmer et al. 1997; Camodeca et al. 1999). However, the mechanisms underlying DHPG-LTD are debated, and both presynaptic (Fitzjohn et al. 2001; Faas et al. 2002; Watabe et al. 2002) as well as postsynaptic mechanisms (Huber et al. 2000; Kleppisch et al. 2001; Snyder et al. 2001; Xiao et al. 2001; Moult et al. 2006) were suggested. A completely different form of LTD can be induced by low-frequency stimulation (LFS-LTD) that depends on postsynaptic NMDA receptor activation and subsequent AMPA receptor dephosphorylation (Lee et al. 2000).

Hyperpolarization-activated cyclic nucleotide-gated nonselective cation channels are assembled of HCN1-HCN4 subunits. HCN1 and HCN2 are predominantly expressed in the hippocampus (Franz et al. 2000; Santoro et al. 2000; Bender et al. 2001) localized on both pyramidal cells (Magee 1999; Santoro et al. 2000) and GABAergic inhibitory interneurons (Maccaferri and McBain 1996; Lupica et al. 2001; Notomi and Shigemoto 2004). One of the most intriguing roles of HCN channels is the modulation of long-term synaptic plasticity. In the present study, we investigated the involvement of HCN channels in LTD at the hippocampal Schaffer collateral-CA1 synapse. We found that pharmacological HCN channel inhibition and genetic HCN1 gene ablation enhanced DHPG-LTD but not LFS-LTD, suggesting differential effects of HCN1 channels on different forms of synaptic plasticity.

\footnotetext{
${ }^{3}$ These authors contributed equally to this work.

${ }^{4}$ Corresponding author.

E-mail timo.kirschstein@uni-rostock.de; fax 49-381-494-8002.

Article is online at http://www.learnmem.org/cgi/doi/10.1101//m.1556009.
}

\section{Results}

HCN channels are involved in Schaffer collateral-CAl synaptic transmission

In order to examine the role of HCN channels on basal synaptic transmission at the Schaffer collateral-CA1 synapse, we used the specific HCN channel blocker ZD7288. As shown in Figure 1A, continuous bath application of $10 \mu \mathrm{M}$ ZD7288 caused a slow timedependent enhancement of the field excitatory postsynaptic potential (fEPSP) slope starting about $10 \mathrm{~min}$ after wash-in, rising up to $151 \pm 15 \%$ after $70 \mathrm{~min}$ (closed circles, $n=7$; Fig. $1 \mathrm{~A}$ ). In contrast, interleaved untreated slices remained stable during the whole experiment (open circles, $n=6$; Fig. 1A), indicating a specific effect of ZD7288 application. Long-term experiments with ZD7288 revealed that the fEPSP slope enhancement saturated after $80 \min (165 \pm 7 \%, n=3)$, which remained stable up to 150 $\min (151 \pm 1 \%, n=3)$. Thus, it is unlikely that the enhancement of fEPSP amplitude by ZD7288 is due to slice deterioration. Next, we investigated whether this effect of ZD7288 is pre- or postsynaptic by analyzing the paired-pulse ratio (PPR). In general, the Schaffer collateral-CA1 synapses display paired-pulse facilitation. We normalized the PPR to pre-drug baseline control values and found that the administration of $10 \mu \mathrm{M}$ ZD7288 was associated with a significant decrease in the normalized PPR compared with interleaved control slices ( $88 \pm 1 \%, n=7, P<0.01$; Fig. 1B), suggesting that HCN channels may be involved in Schaffer collateral-CA1 synaptic transmission via regulation of presynaptic transmitter release rather than modulation of postsynaptic integration.

Since presynaptic HCN channels are abundantly expressed on GABAergic inhibitory interneurons in the hippocampal CA1 region, regulating synaptic transmission by GABA release and tonic inhibition of CA1 pyramidal cells (Lupica et al. 2001), we asked whether the enhancement of synaptic transmission following HCN channel blockade with ZD7288 might be the 


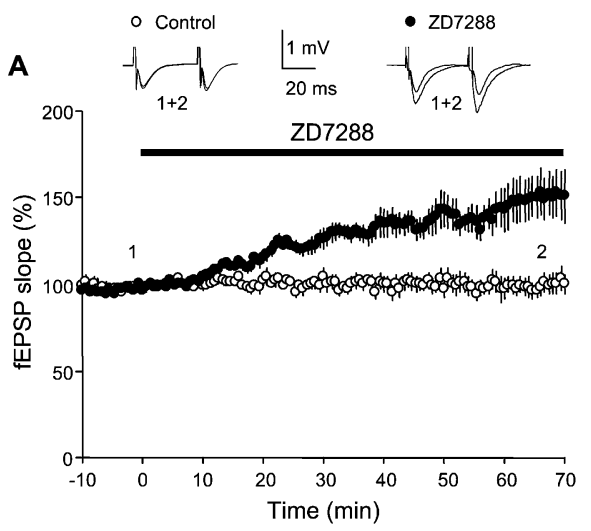

C

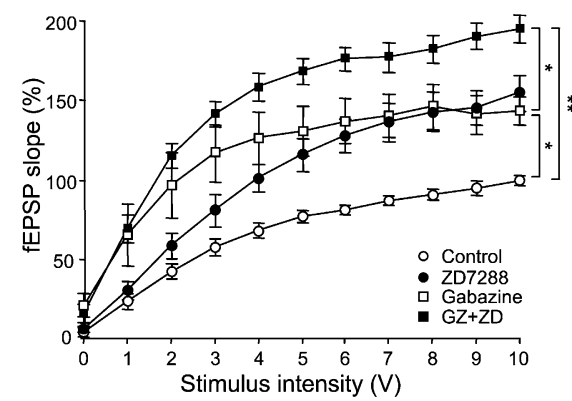

B

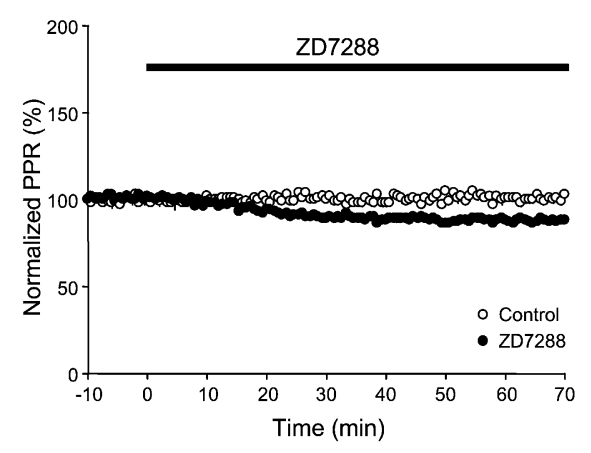

D

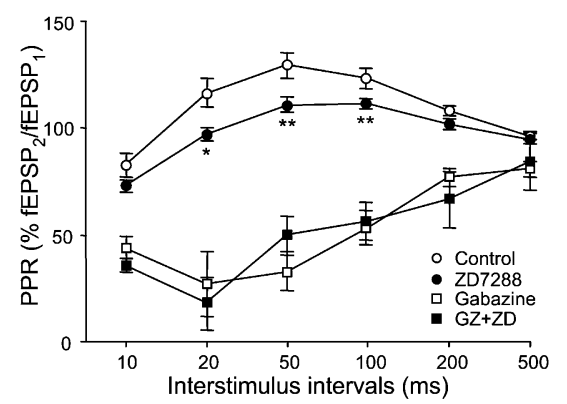

Figure 1. HCN channels modulate Schaffer collateral-CA1 synaptic transmission. (A) Following a 10 -min period of baseline recording, continuous application of ZD7288 $(10 \mu \mathrm{M})$ induced a slow increase of fEPSPs at the Schaffer collateral-CA1 synapse $(\bullet ; n=7)$ compared with interleaved controls $(O ; n=6)$. Representative fEPSPs were taken from the timepoints indicated by numbers. $(B)$ The enhancement of fEPSP induced by ZD7288 was accompanied by a significant decrease in the paired-pulse ratio (PPR) quantified as the normalized ratio of the second to the first fEPSP slope with an ISI of $40 \mathrm{msec}$. (C) Inputoutput relations normalized to control conditions indicated an increase in fEPSP amplitude at different stimulation intensities recorded 60 min after ZD7288 application $(\bullet ; n=7 ; P<0.01)$. Bath application of gabazine $(5 \mu \mathrm{M})$, a specific $G A B A_{A}$ receptor antagonist, significantly enhanced Schaffer collateralevoked fEPSP ( $\square ; n=6 ; P<0.01$ ). An additive amount of increase in fEPSPs was obtained by coapplication of gabazine and ZD7288 $(\mathbf{\square} ; n=5 ; P<0.001)$ as compared with that of gabazine or ZD7288 alone. (D) PPR of two closely spaced stimulations (from 10 to $500 \mathrm{msec}$ ) to Schaffer collaterals demonstrated that ZD7288 significantly depressed the PPR at ISIs between 20 and $100 \mathrm{msec}(\bullet ; n=6)$ compared with baseline control values before drug application $(O ; n=22)$. Gabazine alone caused a significantly stronger depression of the PPR at the ISIs between 20 and $100 \mathrm{msec}(\square ; n=6)$, but no further PPR reduction was observed following coapplication of gabazine and ZD7288 $(\boldsymbol{\square} ; n=5)$.

consequence of a decreased GABA release from interneurons. In accordance with the fEPSP enhancement of ZD7288 from Figure $1 \mathrm{~A}$, the input-output curves normalized to baseline control values before drug application confirmed that the fEPSP slope was significantly higher after ZD7288 treatment (closed circles, $n=7$, $P<0.05$ vs. control; Fig. 1C). Application of gabazine $(5 \mu \mathrm{M})$, a specific $\mathrm{GABA}_{\mathrm{A}}$ receptor antagonist, also significantly enhanced the Schaffer collateral-evoked fEPSP slope (open squares, $n=6, P<$ 0.01 vs. control; Fig. 1C). However, the fEPSP slope was almost doubled by simultaneous coapplication of ZD7288 and gabazine (closed squares, $n=5, P<0.001$ vs. control; $P<0.01$ vs. gabazine or ZD7288; Fig. 1C), indicating an additive effect of these two blockers. When these compounds were subsequently applied, the same results were obtained. In particular, gabazine-mediated fEPSP enhancement could be further increased significantly by ZD7288 application ( $141 \pm 4 \%, n=4$, relative to saturated gabazine response). In turn, gabazine further increased the fEPSPs after saturation of fEPSP enhancement following ZD7288 treatment (138 $\pm 27 \%, n=3$, relative to saturated ZD7288 response). Thus, gabazine and ZD7288 appear to act on different sites when enhancing Schaffer collateral-CA1 synaptic transmission. This finding precludes the sole expression of HCN channels on inhibitory interneurons. Rather, HCN channels may be additionally located either on presynaptic terminals where they could control glutamate release or on postsynaptic dendrites where they would directly interfere with the fEPSP amplitude. To further discriminate between these two possibilities, we carried out a detailed analysis of the paired-pulse plasticity (interstimulus interval [ISI] $=10-500 \mathrm{msec}$ ). ZD7288 significantly reduced the PPR obtained at ISIs of $20-100 \mathrm{msec}$ (closed circles, $n=6, P<0.05$ vs. control; Fig. 1D). In addition, gabazine caused a significantly stronger reduction of the PPR at the ISIs of 10-200 msec (open squares, $n=6, P<$ 0.01 vs. control or ZD7288; Fig. 1D). However, simultaneous coapplication of these two drugs had no further effect on the PPR (closed squares, $n=6$; Fig. 1D) as compared with gabazine alone. Given the additive fEPSP enhancement by coapplication of gabazine and ZD7288, these data are consistent with $\mathrm{HCN}$ channel expression on both interneurons and pyramidal cell dendrites.

To confirm that the ZD7288 bath application used for the field potential measurements actually blocked $\mathrm{HCN}$ channels in our conditions, we impaled CA1 pyramidal cells with sharp microelectrodes and performed intracellular current-clamp recordings. We first obtained $10 \mathrm{~min}$ of baseline recording, followed by $30 \mathrm{~min}$ of ZD7288 $(10 \mu \mathrm{M})$ bath application, and the effect of ZD7288 was assessed by comparing the initial measurements $(0 \mathrm{~min})$ with those at the end of the experiment (40 $\mathrm{min})$. In the first set of experiments, the cells were held at their resting membrane potential $(-68 \pm 1 \mathrm{mV}, n=21)$. Negative current injection (from $-0.1 \mathrm{nA}$ to $-1.4 \mathrm{nA}$, $600 \mathrm{msec}$; see inset in Fig. 2A $\mathrm{A}_{1}$ ) elicited a hyperpolarization of the membrane potential that was significantly enhanced by $60 \%-$ $80 \%$ following ZD7288 (Fig. $2 \mathrm{~A}_{1}$ ) and accompanied by a significant reduction of the depolarizing voltage sag (from $4.3 \pm 1.0 \mathrm{mV}$ to $0.7 \pm 0.4 \mathrm{mV}, P<0.01$; Fig. $2 \mathrm{~A}_{2}$ ). As can be deduced from the current-voltage relations in Figure $2 \mathrm{~A}_{1}$, the membrane resistance was significantly increased by ZD7288 by $63 \pm 18 \%$ (from $32 \pm$ $2 \mathrm{M} \Omega$ to $51 \pm 5 \mathrm{M} \Omega, n=14, P<0.01$; Fig. $2 \mathrm{~A}_{3}$ ). In control experiments, there was only a slight increase of the membrane resistance during the course of the experiment (from $36 \pm 3 \mathrm{M} \Omega$ to $41 \pm 7 \mathrm{M} \Omega$ ), indicating stable recording conditions. In a second set of experiments, the cells were held at $-70 \mathrm{mV}$ by current injection at baseline, which was close to their resting membrane potential. In these recordings, ZD7288 significantly hyperpolarized the membrane potential by about 5-6 mV (closed circles; Fig. 2B), which was not observed in control cells (open circles; Fig. 2B). These intracellular findings demonstrate that bath application of $10 \mu \mathrm{M}$ ZD7288 effectively blocked HCN channels in the CA1 region.

To further investigate the mechanism of enhanced synaptic transmission following HCN channel blockade by ZD7288, we 
$\mathbf{A}_{1}$

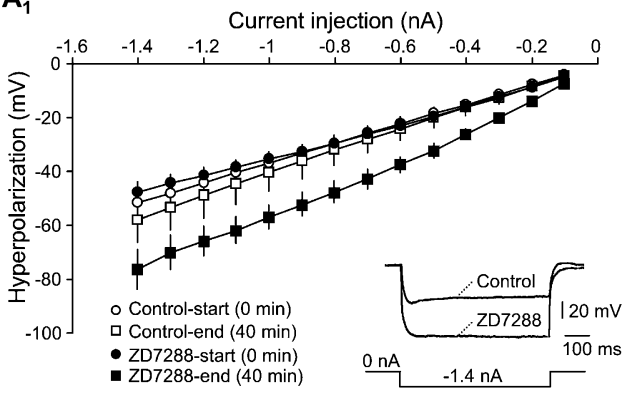

$A_{2}$

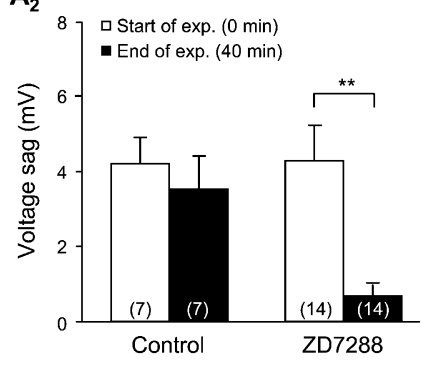

$\mathbf{A}_{3}$

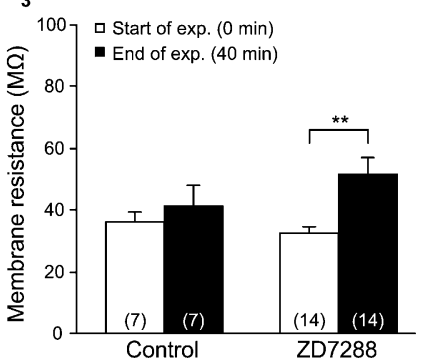

B

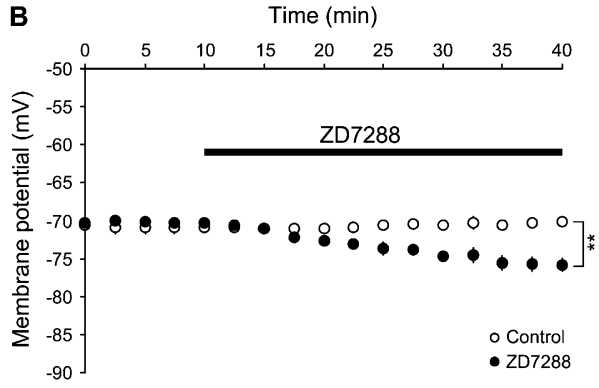

Figure 2. HCN channels modulate membrane potential and membrane resistance. $\left(A_{l}\right)$ Hyperpolarizing current injections (from $-0.1 \mathrm{nA}$ to $-1.4 \mathrm{nA}, 600 \mathrm{msec}$, caused a linear increase in membrane potential which, in control cells (open symbols), was similar at the start ( $0 \mathrm{~min}$ ) and the end of the experiment (40 $\mathrm{min}$ ). However, the linear current-voltage relation was significantly enhanced after the cells were bathed with ZD7288 (•: before ZD7288; $\mathbf{\square}$ : after ZD7288). The inset shows a representative voltage trace recorded during hyperpolarizing current injection at $-1.4 \mathrm{nA}$ before (baseline) and after perfusion of ZD7288. Note the depolarizing voltage sag that disappeared following ZD7288 application. Moreover, the rebound depolarization after hyperpolarization was also abolished after ZD7288. $\left(A_{2}\right)$ The depolarizing voltage sag at the beginning of the experiment was not different between control cells and cells before ZD7288 application (open bars: $4.2 \pm 0.7 \mathrm{mV}$ and $4.3 \pm 1.0 \mathrm{mV}$ respectively). Following ZD7288, the voltage sag was significantly reduced (closed bars: $3.5 \pm 0.9 \mathrm{mV}$ and $0.7 \pm 0.4 \mathrm{mV}$, respectively). $\left(A_{3}\right)$ The membrane resistance at the beginning of the experiment was not different between control cells and cells before ZD7288 application (open bars). Following ZD7288 the membrane resistance was significantly increased (closed bars). (B) The timecourse of the membrane potential held at $-70 \mathrm{mV}$ at baseline $(0-10 \mathrm{~min})$ shows the significant hyperpolarization of cells treated with ZD7288 (indicated by the horizontal bar).

isolated AMPA and NMDA receptor-mediated responses before and after ZD7288 application, while simultaneously recording field potentials (fEPSPs) and intracellular excitatory postsynaptic potentials (EPSPs) (Fig. 3 $\mathrm{A}_{1}$ ). Mirroring field potential data without NMDA receptor blockade (Fig. 1A), isolated AMPA receptor-mediated fEPSPs $(134 \pm 12 \%, n=7, P<0.05)$, and AMPA receptormediated EPSPs recorded intracellularly, were significantly enhanced following ZD7288 (184 $\pm 18 \%, n=7, P<0.01$; Fig. $\left.3 \mathrm{~A}_{2}\right)$. In contrast, isolated NMDA receptor-mediated postsynaptic potentials were decreased after ZD7288 (fEPSPs $72 \pm 8 \%$; EPSPs $79 \pm$ $15 \%$; Fig. $3 \mathrm{~A}_{2}$ ). Since, under normal conditions, glutamatergic responses are practically exclusively AMPA receptor mediated, the enhancement of synaptic transmission by ZD7288 treatment can be explained by increased AMPA receptor-mediated EPSPs. These data therefore confirm the postsynaptic HCN channel location on pyramidal cell dendrites. However, since our paired-pulse plasticity data (Fig. 1D) also suggested an additional presynaptic effect of ZD7288, we recorded NMDA receptor-mediated EPSPs under MK801 treatment. When applying the irreversible, use-dependent blocker of NMDA receptors, MK-801 $(80 \mu \mathrm{M})$, the rate of decline of responses with repetitive stimulation is proportional to the release probability of the glutamatergic synapses (Hessler et al. 1993; Kokaia et al. 1998). Following a baseline recording (in the presence of 6-cyano-7-nitroquinoxaline-2,3-dione disodium [CNQX] and gabazine, stimulation rate $0.066 \mathrm{~Hz}$ ) of $5 \mathrm{~min}$, the stimulation was switched off and MK-801 was bathapplied for $30 \mathrm{~min}$. Then, the stimulation was continued in the presence of MK801 and the decline of NMDA receptormediated EPSPs was determined. This decrease occurred significantly earlier when ZD7288 was coapplied with MK801 as compared with controls $(P<0.05$, Kolmogorov-Smirnov test; Fig. $3 \mathrm{~B}_{1}$ ). Hence, the time constant of stimulations was significantly reduced in slices treated with ZD7288 (39 \pm 5 vs. $65 \pm 8, P<0.05$; Fig. $3 \mathrm{~B}_{2}$ ) indicating enhanced transmitter release probability following $\mathrm{HCN}$ channel blockade. In addition to acting on postsynaptic HCN channels on pyramidal cell dendrites, ZD7288 thus increases glutamatergic transmission at Schaffer collateral-CA1 synapses also presynaptically. These data may indicate that presynaptic $\mathrm{HCN}$ channels control glutamate release from Schaffer collateral terminals.

\section{HCN channels are involved in DHPG-LTD induction, but not expression}

Since one of the most intriguing roles of HCN channels is the modulation of longterm synaptic plasticity, we questioned a possible role of $\mathrm{HCN}$ channels in metabotropic glutamate receptor (mGluR)dependent LTD at Schaffer collateral-CA1 synapses, which can be elicited by a brief application of DHPG, a selective agonist of group I mGluRs. In control experiments, DHPG $(100 \mu \mathrm{M}, 10 \mathrm{~min})$ acutely depressed the fEPSP slope to $59 \pm 6 \%$ of baseline values. This depression partially recovered following DHPG washout, resulting in a stable LTD $(71 \pm 4 \%, n=14, P<0.001$ compared with pre-DHPG baseline) (closed circles; Fig. 4A). In marked contrast, in slices pretreated with ZD7288 $(10 \mu \mathrm{M})$, DHPG induced a strong initial depression of fEPSP slope $(54 \pm 6 \%)$ followed by LTD, which was significantly larger than that observed under control conditions $(62 \pm 7 \%, n=13, P<0.001$ compared with pre-DHPG baseline; Fig. 4B; $P<0.05$ vs. ZD7288untreated slices shown in Fig. 4A). Intriguingly, DHPG-treated slices showed the fEPSP slope enhancement by ZD7288 before DHPG application, but not thereafter, indicating an interaction between mGluRs and $\mathrm{HCN}$ channels. Thus, we questioned whether this interaction can also be observed when ZD7288 is applied 20 min after DHPG washout. The fEPSP slopes during DHPG application and up to $20 \mathrm{~min}$ of DHPG washout were similar to those obtained in control slices. However, when ZD7288 was applied, the fEPSP slopes increased in both interleaved control and DHPG-treated slices $(125 \pm 11 \%, n=14$, and $74 \pm 7 \%, n=13$, respectively; Fig. 4C). From these results we conclude that HCN channels appear to specifically interfere with mGluRs during DHPG-LTD induction.

For the direct comparison of these experiments we normalized the data of DHPG-treated slices to their interleaved control experiments without DHPG as shown in Figure 4D,F. Both the acute depression, as well as the DHPG-LTD level, were significantly enhanced in slices continuously bathed with ZD7288 (black bars, 
$A_{1}$

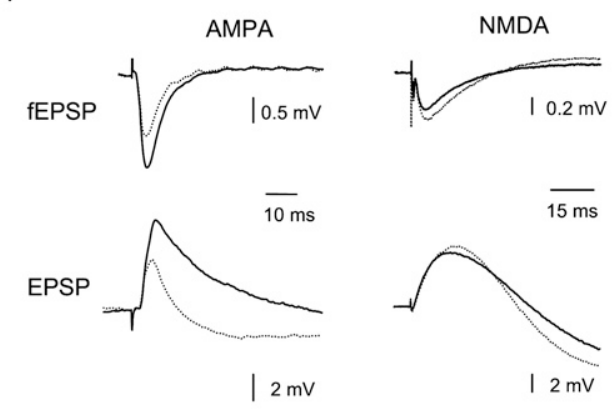

$\mathbf{B}_{1}$

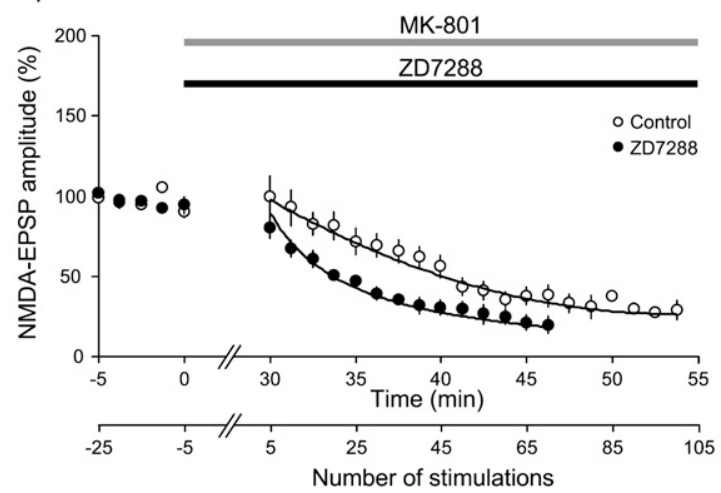

Figure 3. HCN channel blockade enhances AMPA receptor-mediated, but not NMDA receptormediated synaptic transmission-at least in part through a presynaptic mechanism. $\left(A_{1}\right)$ Sample traces recorded during baseline (dotted lines) and perfusion with ZD7288 (solid lines) showing AMPA and NMDA receptor-dependent fEPSPs (top) and intracellularly recorded EPSPs (bottom). $\left(A_{2}\right)$ Bar graphs showing the fEPSP or EPSP amplitude in the presence of ZD7288 normalized to their baseline values. Bath application of ZD7288 enhanced AMPA receptor-mediated fEPSPs and EPSPs (intracellular), but reduced NMDA receptor-mediated responses. Asterisks indicate significant differences in the amplitude obtained under ZD7288 compared with baseline. $\left(B_{1}\right)$ Mean amplitudes of successive NMDA receptormediated EPSPs recorded with repetitive stimulation in the presence of MK-801 in control neurons $(O)$ and in ZD7288-treated neurons $(\bullet)$. Each point represents the mean of five consecutive traces. NMDA receptor-mediated EPSPs decline more rapidly with MK-801 application in ZD7288-incubated slices than in untreated slices, indicating a ZD7288-mediated increase in glutamate release probability. Horizontal bars represent the duration of the application of MK-801 (gray bar) and ZD7288 (black bar). The lines represent the exponential curve fits to the amplitude decay. $\left(B_{2}\right)$ Bar graphs showing the time constant of NMDA receptor-mediated EPSPs in control slices (open bar) and in the slices perfused with ZD7288 (closed bar). The decay rate of evoked EPSPs was significantly faster in neurons perfused with ZD7288 than in controls. with both of the other groups), suggesting a modulation of DHPG-LTD via presynaptic HCN channels on Schaffer collateral terminals.

\section{HCN channels involved in DHPG-LTD are of the HCN1 subtype}

To rule out unspecific effects of ZD7288 (Chevaleyre and Castillo 2002; Chen 2004) and to identify the HCN subunit, we used HCN1 channel knockout mice. The input-output curves for homozygous HCN1 channel knockout mice $\left(\mathrm{HCN1}^{-/-}\right.$, closed circles, Fig. 5A) did not differ significantly from those obtained from wild-type littermates $\left(\mathrm{HCN}^{+/+}\right.$; open circles; Fig. 5A), whereas the PPR for $\mathrm{HCN}^{-/-}$mutants was significantly smaller than the PPR for $\mathrm{HCN1}^{+/+}$mice at the ISIs of 20-100 msec (Fig. 5B). These results confirmed our data with ZD7288 indicating that HCN1 is the responsible subunit for the modulating effects of HCN channels on short-term plasticity. Importantly, DHPG-induced LTD was strongly enhanced in $\mathrm{HCN}^{-1-}$ mice (closed circles, $53 \pm 8 \%, n=9$; Fig. $5 \mathrm{C}$ ) as compared with wild-type littermates (open circles, $81 \pm 5 \%, n=7, P<0.05$; Fig. 5C). In contrast to DHPG-LTD, the levels of NMDA receptor-dependent LFSLTD did not differ between $\mathrm{HCN}^{+/+}$ and $\mathrm{HCN}^{-1-}(77 \pm 9 \%, n=11$ and $79 \pm 5 \%, n=8$, respectively; Fig. 5D,F) without changes of the PPR indicating postsynaptic induction mechanisms (Fig. 5E). Taken together, our data demonstrate that HCN1 channels constrain mGluR-dependent DHPG-LTD, but not NMDA receptor-dependent LFS-LTD at the Schaffer collateral-CA1 pyramidal cell synapse.
$46 \pm 6 \%$ and $41 \pm 4 \%$, respectively, $n=13$ ) compared with control (open bars, $59 \pm 6 \%$ and $71 \pm 4 \%$, respectively, $n=14$ ). Moreover, DHPG-induced LTD in slices treated with ZD7288 after $20 \mathrm{~min}$ of DHPG washout was not different from control conditions, but was significantly less compared with LTD in slices with continuous ZD7288 treatment (gray bars, $58 \pm 5 \%, n=13$ ). These results demonstrate that HCN channel inhibition during DHPG-LTD induction, but not after DHPG washout, significantly enhances DHPG-LTD, suggesting a constraining role of HCN channels in mGluR-dependent LTD induction, but not in LTD expression at Schaffer collateral-CA1 synapses.

To identify the site of ZD7288 action on LTD enhancement, the PPR following DHPG-induced LTD was calculated and normalized to the data of interleaved DHPG-untreated slices. Control slices and slices with ZD7288 application after 20 min of DHPG washout showed a small but significant rise in the PPR $(106 \pm 1 \%$, $n=14$, and $118 \pm 3 \%, n=13$, respectively; both $P<0.05$ compared with pre-DHPG-baseline; Fig. 4E), whereas the slices continuously bathed with solution containing ZD7288 showed a significantly stronger increase in the PPR $(133 \pm 3 \%, n=13, P<0.05$ compared

\section{Discussion}

\section{HCN1 channels modulate synaptic transmission at the Schaffer collateral-CAl synapse}

We have shown that basal synaptic transmission and mGluRdependent LTD, but not NMDA receptor-dependent LTD are modulated by HCN1 channels at Schaffer collateral-CA1 synapses. Blockade of HCN channels by ZD7288 caused a time-dependent increase in fEPSP amplitude, which was accompanied by a decrease in the PPR. This decrease in PPR was confirmed in HCN1 knockout mice, and indicates a presynaptic site of action by HCN1 channel inhibition or ablation. Thus, in our hands, ZD7288 did not cause AMPA receptor inhibition as has been described (Chevaleyre and Castillo 2002; Chen 2004). Moreover, intracellular recordings confirmed the enhancement of AMPA receptor-mediated EPSPs by ZD7288. We therefore propose that the low dosage of ZD7288 used in the present study $(10 \mu \mathrm{M})$, which was clearly effective in HCN channel blockade, did not exert unspecific AMPA receptor inhibition that had been observed at mostly higher concentrations (Chevaleyre and Castillo 2002; Chen 2004). In contrast, the 

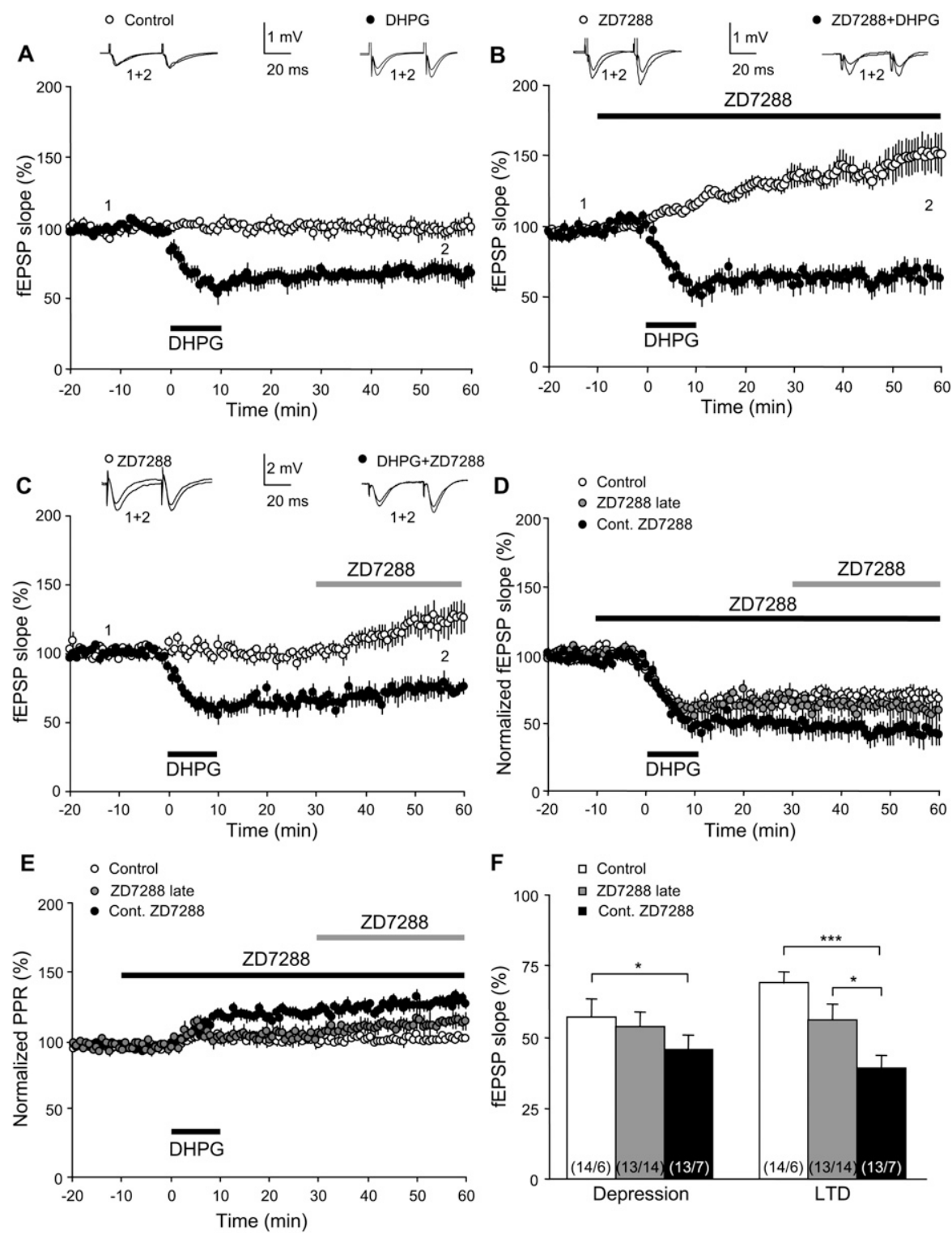

$\mathbf{F}$
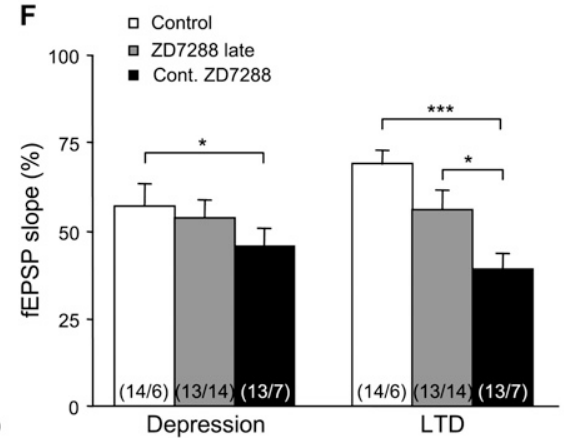

Figure 4. $\mathrm{HCN}$ channels constrain mGluR-dependent LTD induction, but not expression. (A) Metabotropic glutamate receptor (mGluR)-dependent LTD was induced by brief bath application of (RS)-3,5-DHPG (indicated by black bar, $100 \mu \mathrm{M}$ for $10 \mathrm{~min}$; $\bullet$ ). Representative fEPSPs in the inset of each graph were taken at the time indicated by the numbers. Data from control slices without DHPC $(O)$ were taken from Figure 1A for the sake of clarity. (B) In comparison to control slices, DHPG induced more pronounced LTD when slices were incubated in solution containing $10 \mu \mathrm{M}$ ZD7288 (•). Data from ZD7288-treated slices without DHPG $(\bullet)$ were taken from Figure 1A for the sake of clarity. (C) To show the effect of HCN channel blocker on DHPG-LTD expression, ZD7288 was applied 20 min after the LTD induction as indicated by the gray bar. Note that following ZD7288 application, the fEPSPS were gradually enhanced in both interleaved controls and DHPG-treated slices. (D) Summary of all experiments showing DHPG-LTD normalized to their interleaved controls without DHPG application. Note that slices bathed continuously with ZD7288 $(\bullet)$ showed significantly more pronounced DHPGLTD than control slices $(\bigcirc)$ as well as slices with ZD7288 application after DHPG washout (gray circles). (E) Comparison of the concomitant change in the PPR (calculated as the ratio of the slope of the second pulse-evoked fEPSP to the first pulse-evoked fEPSP) of DHPG-treated slices normalized to DHPGuntreated slices following DHPG-LTD. Control slices $(O)$ and slices in which ZD7288 was applied after DHPG washout (gray circles) showed a small but significant rise in the PPR, whereas in the slices continuously bathed with solution containing ZD7288 (•), the PPR was even significantly stronger compared with both of the other experimental groups. ( $($ ) Bar graphs comparing DHPG-induced acute depression and LTD. Both acute depression (DEP) as well as DHPG-LTD were significantly enhanced in slices continuously perfused with ZD7288-containing solution (closed bars) compared with that of control slices (open bars) or slices in which ZD7288 was applied after LTD induction (gray bars). The numbers of all groups are given in brackets (number of DHPG-treated slices/number of DHPGuntreated slices). concentration needed to block NMDA receptors appears to be much lower, since NMDA receptor-mediated responses were decreased following ZD7288, as had been reported before (Chen 2004).

Previous reports have suggested that HCN channels are present at excitatory presynaptic terminals and may modulate transmitter release in the chick ciliary ganglion (Fletcher and Chiappinelli 1992), the crayfish neuromuscular junction (Beaumont and Zucker 2000), the rat calyx of Held synapse (Cuttle et al. 2001), and in the hippocampus (Bender et al. 2007). On the other hand, there is abundant evidence for presynaptic HCN channels on GABAergic inhibitory interneurons (Svoboda and Lupica 1998; Southan et al. 2000; Lupica et al. 2001; Aponte et al. 2006). Gasparini and DiFrancesco (1997) previously observed that the presence of ZD7288 strongly reduced IPSPs following stimulation of Schaffer collaterals and suggested that the major component of the inhibitory input to CA1 pyramidal neurons was controlled by an HCN channel-dependent mechanism. Furthermore, Lupica et al. (2001) have reported that interneuronal HCN channels facilitate GABA release onto CA1 pyramidal neurons by regulating the resting membrane potential. However, these mechanisms can only partly explain our present results. One possibility is that presynaptic HCN1 channels are directly involved in transmitter release at the glutamatergic Schaffer collateral-CA1 synapse. Since application of the $\mathrm{GABA}_{\mathrm{A}}$ receptor antagonist gabazine strongly enhanced the Schaffer collateral-evoked fEPSP amplitude with a concomitant drop of the PPR, our results may be explained by an indirect fEPSP enhancement via presynaptic inhibition of Schaffer collateral terminals, rather than via modulating the GABAergic input on pyramidal cell dendrites. Thus, presynaptic HCN channels on GABAergic interneurons cannot be excluded. However, inhibition of both $\mathrm{GABA}_{\mathrm{A}}$ receptors and $\mathrm{HCN}$ channels should not have a larger effect than the individual drugs alone, if only GABAergic terminals had presynaptic HCN channels. Quite contrary to that, we actually found a significantly additive effect of these two blockers, indicating a partly independent site of action of $\mathrm{GABA}_{\mathrm{A}}$ receptors and HCN channels. We believe this may be most parsimoniously explained by additional presynaptic HCN channels on Schaffer collateral terminals. The intracellular recordings with MK-801 confirmed the enhanced glutamate release probability following ZD7288. Moreover, our knockout data indicate the predominant role of the 
A
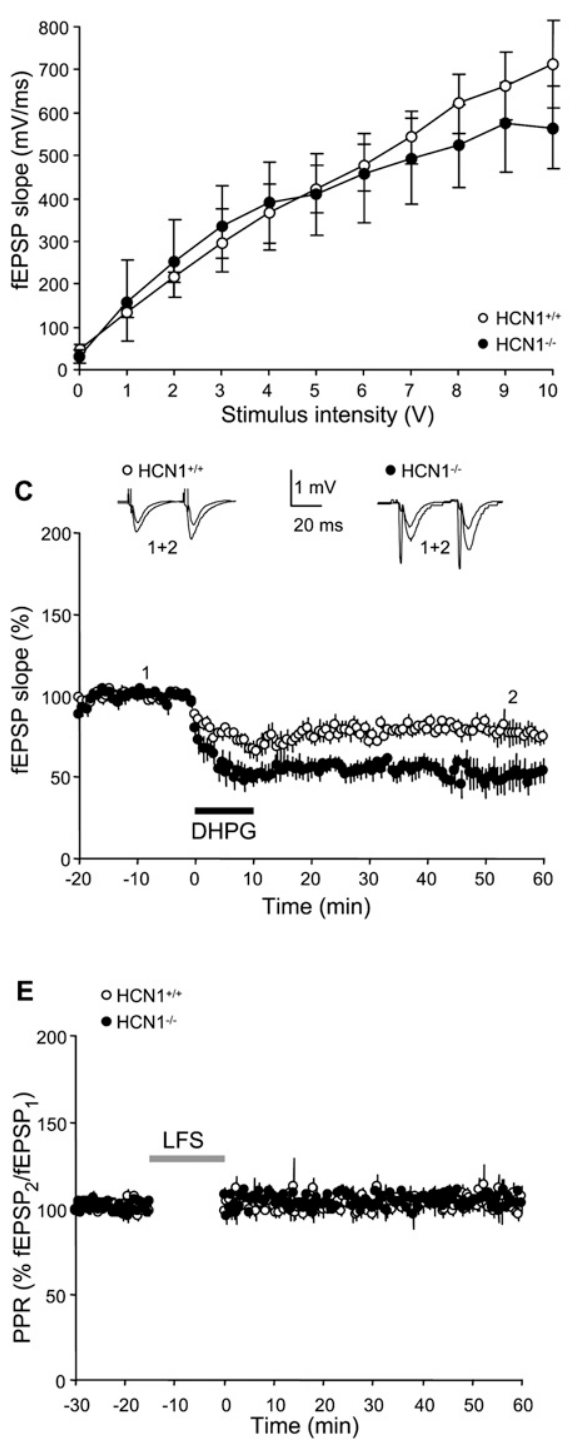

B
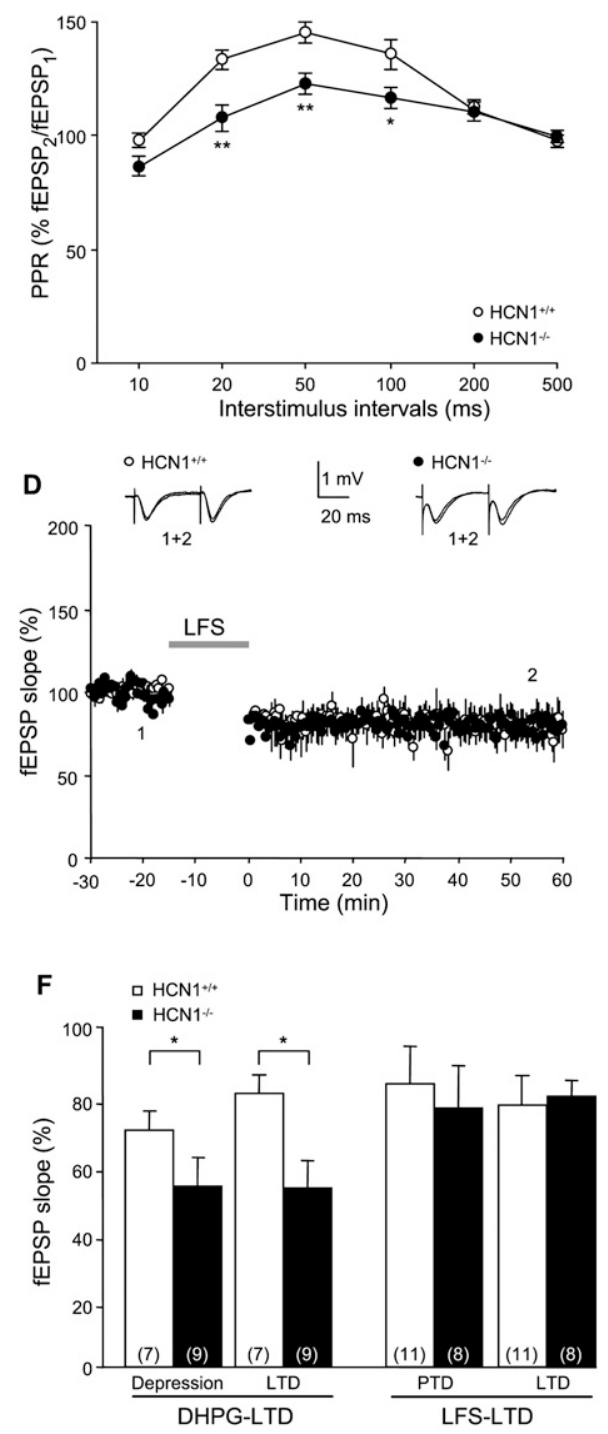

Figure 5. $\mathrm{HCN}^{-1-}$ mice show enhanced mGluR-dependent LTD, but not NMDAR-dependent LTD. (A) The input-output curves for homozygous $\left(\mathrm{HCN1}^{-1-} ; \bullet ; n=11\right)$ mice did not differ significantly from those obtained from wild-type littermates $\left(\mathrm{HCN1}^{+/+} ; \mathrm{O}, n=7\right)$. (B) The PPR for $\mathrm{HCN} 1^{-/-}$was significantly smaller than the PPR for $\mathrm{HCN1}^{+/+}$mice at the ISIs of $20-100 \mathrm{msec}(P<0.01$ for ISI of 20-50 msec and $P<$ 0.05 for ISI of $100 \mathrm{msec}$ ). (C) DHPG-LTD in the mouse CA1-Schaffer collateral pathway. LTD was strongly enhanced in HCN1 homozygous mutant $(\bullet)$ mice as compared with wild-type littermate controls $(\bigcirc)$. (D) Low-frequency stimulation (LFS indicated by the gray bar consisting of 900 pulses for 15 min at $1 \mathrm{~Hz}$ ) induced significant LTD in both $\mathrm{HCN1}^{+/+}(\mathrm{O})$ and $\mathrm{HCN1}^{-/-}(\bullet)$ mice compared with their baseline values. (E) The timecourse of the PPR normalized to pre-LFS baseline did not show any change in either experimental group after LFS induction. ( $F$ ) The comparison of all LTD experiments in mice revealed that the amounts of DHPG-induced acute depression (DEP) and DHPG-LTD in $\mathrm{HCN}^{-1-}$ were significantly different from those of $\mathrm{HCN1}^{+/+}(P<0.05)$, whereas the amounts of post-tetanic depression (PTD) and LFS-LTD in $\mathrm{HCN}^{+/+}$and $\mathrm{HCN1}^{-/-}$mice turned out to not be different.

HCN1 subunit in controlling transmitter release at these synapses. This is also consistent with previous studies that have reported HCN1 (mRNA) as the major subunit expressed in the CA1 region (Franz et al. 2000; Santoro et al. 2000; Bender et al. 2001).

\section{HCN1 channels modulate DHPG-LTD at the Schaffer collateral-CAl synapses}

In the second part of our study, we observed an impairing role of HCN channels on DHPG-LTD at Schaffer collateral-CA1 synapses using both ZD7288 and HCN1 gene ablation. As a methodological aspect, LTD generation is generally facilitated by decreased inhibition or hyperexcitable $\left(0 \mathrm{Mg}^{2+}\right)$ conditions (Palmer et al. 1997), although under our experimental conditions, blockade of inhibition with the $\mathrm{GABA}_{\mathrm{A}}$ receptor antagonist gabazine did not enhance DHPG-induced LTD (Rohde et al. 2009). Since, in our hands LTD could thus be induced sufficiently under normal conditions, we refrained from any further manipulation of the GABAergic system or the ionic microenvironment for the present study. Up to now, the cellular mechanisms underlying DHPG-LTD still remain ambiguous. While presynaptic expression mechanisms have been suggested on the basis that it was associated with an increase in the PPR (Fitzjohn et al. 2001; Faas et al. 2002; Watabe et al. 2002), there is almost equal evidence arguing strongly in favor of postsynaptic changes (Huber et al. 2000; Kleppisch et al. 2001; Snyder et al. 2001; Xiao et al. 2001; Moult et al. 2006). In the present study, DHPG-LTD was accompanied by a rise in the PPR, supporting presynaptic mechanisms by reducing transmitter release probability, even though it was not the aim of this study to explore the site of DHPG-LTD expression. More importantly, however, we found that the amount of DHPGinduced LTD and the concomitant PPR increase was significantly enhanced by the presence of ZD7288, suggesting a presynaptic modulation of DHPG-LTD via $\mathrm{HCN}$ channels. Since an increase of membrane resistance leads to an increase of EPSPs (and fEPSPs), the suppressive effect of ZD7288 in LTD induction is likely to be underestimated.

But how might presynaptic $\mathrm{HCN}$ channels regulate transmitter release at excitatory synapses? The mechanisms by which presynaptic HCN channels modulate transmitter release at excitatory synapses are far from understood: They may differ between individual synapses (Nolan et al. 2004) and may depend on presynaptic firing frequencies (Aponte et al. 2006; Bender et al. 2007). We have recently shown that in the mammalian hippocampus presynaptic HCN channel blockade can enhance short-term depression at the immature medial perforant path-granule cell synapse (Bender et al. 2007). Likewise, in our present study, HCN channel inhibition and HCN1 gene ablation caused an enhancement of DHPG-LTD. Further studies are necessary to shed more light on presynaptic HCN channels and their impact on transmitter release probability.

\section{Materials and Methods}

\section{Slice preparation and maintenance}

Male 2-3-mo-old Sprague-Dawley rats (Charles River Laboratories) or 30-50 d-old HCN1 knockout mice were used according to the 
guidelines by the Animal Care and Use Committee. For the HCN1 knockout experiments two pairs of homozygous HCN1-deficient mice $\left(\mathrm{HCN} 1^{-1-}\right)$ and the corresponding controls were purchased from Jackson Laboratory (Bar Harbor, ME) and bred at the Institute of Physiology, Rostock, Germany.

After deep anesthesia with diethyl ether, animals were decapitated and the brain was rapidly removed and submerged into oxygenated ice-cold dissection solution containing (in millimolars) $125 \mathrm{NaCl}, 26 \mathrm{NaHCO}_{3}, 3 \mathrm{KCl}, 1.25 \mathrm{NaH}_{2} \mathrm{PO}_{4}, 0.2 \mathrm{CaCl}_{2}$, $5 \mathrm{MgCl}_{2}$, and $13 \mathrm{D}$-glucose (gassed with $95 \% \mathrm{O}_{2}, 5 \% \mathrm{CO}_{2}$ at $\mathrm{pH}$ 7.4). Horizontal brain slices $(400 \mu \mathrm{m})$ of the hippocampus were prepared using a vibratome, and then transferred into a holding chamber with artificial cerebrospinal fluid (ACSF) containing (in millimolars) $125 \mathrm{NaCl}, 26 \mathrm{NaHCO}_{3}, 3 \mathrm{KCl}, 1.25 \mathrm{NaH}_{2} \mathrm{PO}_{4}$, $2.5 \mathrm{CaCl}_{2}, 1.3 \mathrm{MgCl}_{2}$, and $13 \mathrm{D}$-glucose (gassed with $95 \% \mathrm{O}_{2}$, $\left.5 \% \mathrm{CO}_{2} ; \mathrm{pH} 7.4\right)$.

\section{Electrophysiological recording and analysis}

Field excitatory postsynaptic potentials (fEPSPs) were recorded at $32^{\circ} \mathrm{C}$ (TC-10, npi electronic $\mathrm{GmbH}$ ) using borosilicate glass pipettes (2-3 M $\Omega$, pulled with PIP5 from HEKA Elektronik) filled with ACSF. Paired-pulse bipolar stimulation (ISI $40 \mathrm{msec}$ ) was delivered with a Master-8 stimulator (AMPI) at a rate of $0.025 \mathrm{~Hz}$, and baseline stimulation strength adjusted to $30 \%-40 \%$ of the maximal fEPSP amplitude. Amplified signals were filtered at $1 \mathrm{kHz}$ (EXT10-2F, npi), digitized (Micro1401, CED, Cambridge Electronic Design) and analyzed (Signal 2.16, CED). The mGluR-dependent LTD was induced by bath application of (RS)-3,5-DHPG. The NMDA receptor-dependent LTD was induced by low-frequency stimulation (LFS) consisting of 900 stimuli at $1 \mathrm{~Hz}(15 \mathrm{~min})$ administered at double-baseline stimulation intensity. The PPR at an ISI of $40 \mathrm{msec}$ was calculated as the ratio of the slope of the second pulse-evoked fEPSP to the first pulse-evoked fEPSP.

Intracellular recordings were performed in CA1 pyramidal cells impaled with borosilicate glass microelectrodes (80-120 M $\Omega$, pulled with P-97, Sutter Instrument, and filled with $3 \mathrm{M}$ potassium acetate and $0.3 \mathrm{M} \mathrm{KCl}$ ) using an SEC-05 amplifier (npi) at $32^{\circ} \mathrm{C}$ (TC-10, npi). In these recordings the membrane potential, the membrane resistance, and the depolarizing voltage sag upon hyperpolarizing current injection were measured in order to assess the ZD7288 effect. The membrane resistance was calculated as the slope of the current-voltage curve obtained by hyperpolarizing current injection (from $-0.1 \mathrm{nA}$ to $-1.4 \mathrm{nA}$ ). The depolarizing voltage sag was measured as the difference between the minimum of the hyperpolarizing membrane potential and the steady-state membrane potential at the end of the current injection $(-1.4 \mathrm{nA}$ for $600 \mathrm{msec}$, see inset of Fig. 2A $\mathrm{A}_{1}$ ). AMPA receptor-mediated excitatory postsynaptic potentials (EPSPs) were recorded in the presence of D-(-)-2-amino-5-phosphonopentanoic acid (D-AP5, $50 \mu \mathrm{M})$. NMDA receptor-mediated EPSPs were recorded in gabazine $(5 \mu \mathrm{M})$ and 6-cyano-7-nitroquinoxaline-2,3-dione disodium $(\mathrm{CNQX}, 10 \mu \mathrm{M})$. To gage the impact of HCN channels on presynaptic mechanisms, experiments with the irreversible usedependent NMDA receptor blocker (5S,10R)-(+)-5-methyl-10,11dihydro-5H-dibenzo[a,d]cyclohepten-5,10-imine maleate (MK$801,80 \mu \mathrm{M}), \mathrm{CNQX}$ and gabazine $(5 \mu \mathrm{M})$ at a stimulation frequency of $0.066 \mathrm{~Hz}$ were performed in the presence and absence of ZD7288 (Hessler et al. 1993; Kokaia et al. 1998).

Gabazine, (RS)-3,5-DHPG, CNQX, D-AP5, MK-801, and ZD7288 were purchased from Tocris. All other chemicals were purchased from Sigma. All data are expressed as means \pm SEM. Statistical comparisons were performed using the Student's two-tailed $t$-test, analysis of variance (ANOVA), or KolmogorovSmirnov test. The level of significance is indicated by asterisks: $\left(^{*}\right)$ $\left.P<0.05 ;{ }^{* *}\right) P<0.01 ;\left({ }^{* * *}\right) P<0.001$.

\section{Acknowledgments}

We thank Katrin Porath and Ulrike Mikkat for excellent technical assistance. This study was supported by the German Research Council (Deutsche Forschungsgemeinschaft, grant KI 1283/3-1) and intramural research funding (FORUN, Medical Faculty, University of Rostock).

\section{References}

Aponte Y, Lien CC, Reisinger E, Jonas P. 2006. Hyperpolarization-activated cation channels in fast-spiking interneurons of rat hippocampus. J Physiol 574: 229-243.

Beaumont V, Zucker RS. 2000. Enhancement of synaptic transmission by cyclic AMP modulation of presynaptic $I_{h}$ channels. Nat Neurosci 3: 133141.

Bender RA, Brewster A, Santoro B, Ludwig A, Hofmann F, Biel M, Baram TZ. 2001. Differential and age-dependent expression of hyperpolarizationactivated, cyclic nucleotide-gated cation channel isoforms 1-4 suggests evolving roles in the developing rat hippocampus. Neuroscience 106: 689-698.

Bender RA, Kirschstein T, Kretz O, Brewster AL, Richichi C, Rüschenschmidt C, Shigemoto R, Beck H, Frotscher M, Baram TZ. 2007. Localization of HCN1 channels to presynaptic compartments: Novel plasticity that may contribute to hippocampal maturation. J Neurosci 27: 46974706.

Camodeca N, Breakwell NA, Rowan MJ, Anwyl R. 1999. Induction of LTD by activation of group I mGluR in the dentate gyrus in vitro. Neuropharmacology 38: 1597-1606.

Chen C. 2004. ZD7288 inhibits postsynaptic glutamate receptor-mediated responses at hippocampal perforant path-granule cell synapses. Eur J Neurosci 19: 643-649.

Chevaleyre V, Castillo PE. 2002. Assessing the role of $\mathrm{I}_{\mathrm{h}}$ channels in synaptic transmission and mossy fiber LTP. Proc Natl Acad Sci 99: 95389543.

Cuttle MF, Rusznak Z, Wong AY, Owens S, Forsythe ID. 2001. Modulation of a presynaptic hyperpolarization-activated cationic current $\left(\mathrm{I}_{\mathrm{h}}\right)$ at an excitatory synaptic terminal in the rat auditory brainstem. JPhysiol 534: 733-744.

Faas GC, Adwanikar H, Gereau RW, Saggau P. 2002. Modulation of presynaptic calcium transients by metabotropic glutamate receptor activation: A differential role in acute depression of synaptic transmission and long-term depression. J Neurosci 22: 6885-6890.

Fitzjohn SM, Palmer MJ, May JE, Neeson A, Morris SA, Collingridge GL. 2001. A characterisation of long-term depression induced by metabotropic glutamate receptor activation in the rat hippocampus in vitro. J Physiol 537: 421-430.

Fletcher GH, Chiappinelli VA. 1992. An inward rectifier is present in presynaptic nerve terminals in the chick ciliary ganglion. Brain Res $\mathbf{5 7 5}$ : 103-112.

Franz O, Liss B, Neu A, Roeper J. 2000. Single-cell mRNA expression of HCN1 correlates with a fast gating phenotype of hyperpolarizationactivated cyclic nucleotide-gated ion channels (Ih) in central neurons. Eur J Neurosci 12: 2685-2693.

Gasparini S, DiFrancesco D. 1997. Action of the hyperpolarization-activated current $\left(I_{\mathrm{h}}\right)$ blocker ZD7288 in hippocampal CA1 neurons. Pflugers Arch 435: 99-106.

Hessler NA, Shirke AM, Malinow R. 1993. The probability of transmitter release at a mammalian central synapse. Nature 366: 569-572.

Huber KM, Kayser MS, Bear MF. 2000. Role for rapid dendritic protein synthesis in hippocampal mGluR-dependent long-term depression. Science 288: 1254-1257.

Kleppisch T, Voigt V, Allmann R, Offermanns SG. 2001. G ${ }^{\alpha}$ q-Deficient mice lack metabotropic glutamate receptor-dependent long-term depression but show normal long-term potentiation in the hippocampal CA1 region. J Neurosci 21: 4943-4948.

Kokaia M, Asztely F, Olofsdotter K, Sindreu CB, Kullmann DM, Lindvall O. 1998. Endogenous neurotrophin-3 regulates short-term plasticity at lateral perforant path-granule cell synapses. J Neurosci 18: 87308739.

Lee HK, Barbarosie M, Kameyama K, Bear MF, Huganir RL. 2000. Regulation of distinct AMPA receptor phosphorylation sites during bidirectional synaptic plasticity. Nature 405: 955-959.

Lupica CR, Bell JA, Hoffman AF, Watson J. 2001. Contribution of the hyperpolarization-activated current $\left(I_{\mathrm{h}}\right)$ to membrane potential and GABA release in hippocampal interneurons. J Neurophysiol 86: 261268.

Maccaferri G, McBain CJ. 1996. Long-term potentiation in distinct subtypes of hippocampal nonpyramidal neurons. J Neurosci 16: 5334-5343.

Magee JC. 1999. Dendritic Ih normalizes temporal summation in hippocampal CA1 neurons. Nat Neurosci 2: 508-514.

Moult PR, Gladding CM, Sanderson TM, Fitzjohn SM, Bashir ZI, Molnar E, Collingridge GL. 2006. Tyrosine phosphatases regulate AMPA receptor trafficking during metabotropic glutamate receptor-mediated long-term depression. J Neurosci 26: 2544-2554.

Nolan MF, Malleret G, Dudman JT, Buhl DL, Santoro B, Gibbs E, Vronskaya S, Buzsaki G, Siegelbaum SA, Kandel ER, et al. 2004. A behavioral role for dendritic integration: HCN1 channels constrain spatial memory and plasticity at inputs to distal dendrites of CA1 pyramidal neurons. Cell 119: 719-732. 
Notomi T, Shigemoto R. 2004. Immunohistochemical localization of $\mathrm{I}_{\mathrm{h}}$ channel subunits, HCN1-4, in the rat brain. J Comp Neurol 471: 241-276.

Palmer MJ, Irving AJ, Seabrook GR, Jane DE, Collingridge GL. 1997. The group I mGlu receptor agonist DHPG induces a novel form of LTD in the CA1 region of the hippocampus. Neuropharmacology 36: 1517-1532.

Rohde M, Tokay T, Köhling R, Kirschtein T. 2009. GABA receptor inhibition does not affect mGluR-dependent LTP at hippocampal Schaffer collateral-CA1 synapses. Neurosci Lett 467: 20-25.

Santoro B, Chen S, Luthi A, Pavlidis P, Shumyatsky GP, Tibbs GR, Siegelbaum SA. 2000. Molecular and functional heterogeneity of hyperpolarization-activated pacemaker channels in the mouse CNS J Neurosci 20: 5264-5275.

Snyder EM, Philpot BD, Huber KM, Dong X, Fallon JR, Bear MF. 2001. Internalization of ionotropic glutamate receptors in response to $\mathrm{mGluR}$ activation. Nat Neurosci 4: 1079-1085.
Southan AP, Morris NP, Stephens GJ, Robertson B. 2000. Hyperpolarizationactivated currents in presynaptic terminals of mouse cerebellar basket cells. J Physiol 526: 91-97.

Svoboda KR, Lupica CR. 1998. Opioid inhibition of hippocampal interneurons via modulation of potassium and hyperpolarizationactivated cation $\left(I_{\mathrm{h}}\right)$ currents. $J$ Neurosci 18: 7084-7098.

Watabe AM, Carlisle HJ, O'Dell TJ. 2002. Postsynaptic induction and presynaptic expression of group $1 \mathrm{mGluR}$-dependent LTD in the hippocampal CA1 region. J Neurophysiol 87: 1395-1403.

Xiao MY, Zhou Q, Nicoll RA. 2001. Metabotropic glutamate receptor activation causes a rapid redistribution of AMPA receptors. Neuropharmacology 41: 664-671.

Received July 24, 2009; accepted in revised form September 23, 2009. 


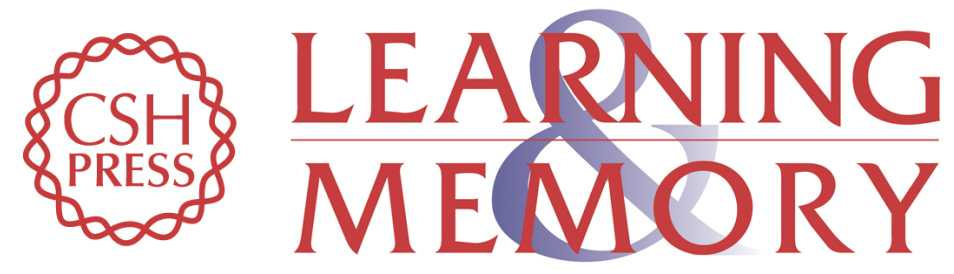

\section{HCN1 channels constrain DHPG-induced LTD at hippocampal Schaffer collateral-CA1 synapses}

Tursonjan Tokay, Marco Rohde, Sabine Krabbe, et al.

Learn. Mem. 2009, 16:

Access the most recent version at doi:10.1101//m.1556009

References This article cites 32 articles, 10 of which can be accessed free at:

http://learnmem.cshlp.org/content/16/12/769.full.html\#ref-list-1

License

Email Alerting Receive free email alerts when new articles cite this article - sign up in the box at the Service top right corner of the article or click here. 